\title{
The value of intra-operative ultrasonography on safety margin and outcome during liver resection and radio-frequency ablation
} \section{in the management of hepatocellular carcinoma patients}

Mohamed Mogahed ${ }^{1 *}$, Ashraf Anas Zytoon² ${ }^{\mathbb{D}}$, Ahmed Abdel Haleem³ ${ }^{3}$ ElSayed Imam³ ${ }^{3}$ Nashwa Ghanem ${ }^{4}$ and Wessam M. Abdellatif ${ }^{5}$

\begin{abstract}
Background: Hepatocellular carcinoma (HCC) is an important health issue worldwide. Liver resection is the optimal management for early compensated HCC patients, but the majority of HCC patients are not candidates for resection. Several nonsurgical treatment modalities such as radio-frequency ablation (RFA), microwave ablation (MWA), transarterial chemoembolization, and immune therapy have been established. Intra-operative ultrasound (IOUS) is essential for accurate staging and secures both resection and RFA. We aimed to detect the value of using IOUS on safety margin and outcome during liver resection and RFA in the management of HCC patients. In the current study, 76 HCC patients, 58 males and 18 females, were included. Patients' age ranged from 49 to 69 years. Patients were divided into two groups: 52 open surgery liver resections (open resection group) and 24 laparoscopic-assisted RFA guided with laparoscopic IOUS (LARFA group). The open resection group was further subdivided into 32 cases for whom IOUS was performed and 20 patients studied retrospectively without IOUS. Surgical decisions were based on preoperative ultrasonography, computed tomography, and/or magnetic resonance imaging (MRI). We determined the size, number of lesions, and location by IOUS and compared them with preoperative imaging. Histopathology was done for resected lesions and follow-up CT for all patients.

Results: In the open resection group, the 32 cases of 52 for whom IOUS was performed, all had free surgical margin (100\%) while 18 of 20 patients studied retrospectively without IOUS had free surgical margin (90\%). Patients operated guided by IOUS had less morbidity and mortality with less operative time and hospital stay. In the LARFA group (24 patients with 37 lesions), the one-month follow-up showed complete ablation for all lesions in the 24 patients, while 12-month follow-up proved two cases of recurrence.
\end{abstract}

Conclusions: IOUS is a cornerstone in liver surgery. It improves outcomes with less morbidity and mortality and helps to achieve free surgical margin. Using IOUS allows the performance of radical but conservative hepatic resection.

\footnotetext{
*Correspondence: mogahed1968@yahoo.com

1 Surgical Department, National Hepatology and Tropical Medicine

Research Institute, Cairo, Egypt

Full list of author information is available at the end of the article
} original author(s) and the source, provide a link to the Creative Commons licence, and indicate if changes were made. The images or other third party material in this article are included in the article's Creative Commons licence, unless indicated otherwise in a credit line to the material. If material is not included in the article's Creative Commons licence and your intended use is not permitted by statutory regulation or exceeds the permitted use, you will need to obtain permission directly from the copyright holder. To view a copy of this licence, visit http://creativecommons.org/licenses/by/4.0/. 
Keywords: (HCC) Hepatocellular carcinoma, Hepatic surgery, (IOUS) intraoperative ultrasonography, (RFA) radiofrequency ablation, (LARFA) laparoscopic-assisted radio-frequency ablation

\section{Background}

Hepatocellular carcinoma (HCC) is an important health issue worldwide. It is the sixth most common cancer and the third cause of cancer death [1]. Liver resection is the optimal management for early compensated HCC patients, but the majority of HCC patients are not candidates for resection. Several nonsurgical treatment modalities such as RFA, MWA, trans-arterial chemoembolization, and immune therapy have been established [2]. RFA is accepted as a treatment for early HCC in several international guidelines [3-5]. We can do RFA percutaneous, through laparotomy or laparoscopy $[6,7]$. The technique of RFA induces localized thermal destruction by heating the tumor tissue to temperatures that exceed $60{ }^{\circ} \mathrm{C}[8]$.

The main challenge during liver resection operations and RFA is the completeness of tumor resection or ablation to prevent recurrence of tumors with a safety margin of $5 \mathrm{~mm}-10 \mathrm{~mm}$ in the normal parenchyma [8]. Laparoscopic intra-operative ultrasound (LIOUS) allows $25 \%$ of new HCC nodules to be detected and allows for much more accurate staging $[9,10]$. Intra-operative ultrasound (IOUS), due to the higher detection rate of hepatic lesions than preoperative CT or MRI, can modify the preoperative treatment strategy in $20-44 \%$ of patients $[11,12]$ and can change the surgical decision for HCC patients [13].

The American Hepato-Pancreato-Biliary Association supported the use of MRI over CT; however, both tend to have low sensitivity to small lesions $<1 \mathrm{~cm}$ [14]. In addition to disease staging, IOUS is beneficial for guiding resection, accurately describes the hepatic segmental boundaries and the tumor's margins themselves, and overcomes large anatomic variations. IOUS enables a three-dimensional tumor and hepatic vessel reconstruction. Localization is important for the preparation of each patient's surgical approach which should be individualized [13]. Under IOUS guidance, RFA is used to create and secure a coagulative ablation of the tumor and the zone around it [15].

This study aims to detect the value of using IOUS on safety margin and outcome during liver resection and LARFA in the management of HCC patients.

\section{Methods}

In the current study, 76 HCC patients, 58 males and 18 females, were included. Patients' median age is 58 and ranged from 49 to 69 years. Patients were divided into two groups: 52 open surgery liver resections (open

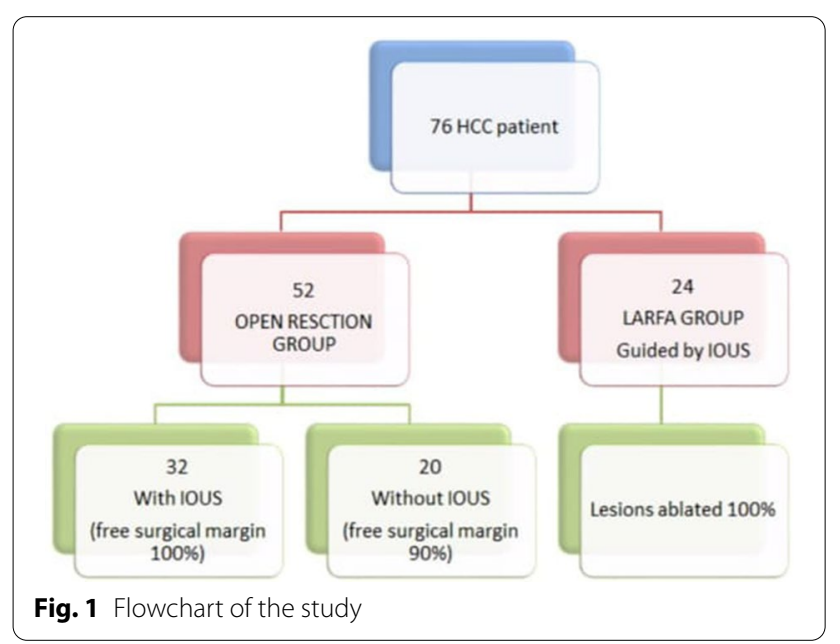

Table 1 Description of patients included in the study

\begin{tabular}{ll}
\hline Number of patients & $\mathbf{7 6}$ \\
\hline Male/female & $58 / 18$ \\
Median age (years) & 58 \\
Within Milan criteria $n(\%)$ & $76(100 \%)$ \\
BCLC Stage A $n(\%)$ & $76(100 \%)$ \\
Open resection group: $n$ & 52 patient \\
With IOUS & 32 \\
Without IOUS & 20 \\
LARFA group $n$ & 24 patient \\
\hline
\end{tabular}

LARFA Laparoscopic-assisted radio-frequency ablation, IOUS Intra-operative ultrasound, $B C L C$ Barcelona-clinic liver cancer staging system for hepatocellular carcinoma

resection group) and 24 laparoscopic-assisted RFA guided with laparoscopic IOUS (LARFA group). The open resection group was further subdivided into 32 cases for whom IOUS was performed and 20 patients studied retrospectively without IOUS (Fig. 1).

The description of patients included in the study is in Table 1.

This combined prospective and retrospective study was performed from January 2017 to March 2020. Patients were recruited from NHTMRI surgical and medical out patients clinics and HCC committee. The paper was approved by local ethical committee of General Organization of Teaching hospitals and Institutes (GOTHI) [number ITH00105/2017] and consent forms were signed 
by all patients after detailed explanation of the procedure and possible complications.

Patient inclusion criteria: patient with HCC lesions all patients are within Milan criteria and class A disease Barcelona Clinic Liver Cancer (BCLC).

Exclusion criteria: Child $\mathrm{C}$ patients with $\mathrm{HCC}$ lesion and for (LARFA group) patients with HCC lesions more than $5 \mathrm{~cm}$ were excluded.

For all patient's clinical history, examination and laboratory investigations and alpha-fetoprotein were done. The surgical decision was based on ultrasonography, triphasic CT, and/or dynamic MRI preoperative. Histopathology was done for resected lesions, and follow-up CT was done for all patients.

The radiological appearance of hepatocellular carcinomas We performed preoperative ultrasound and Doppler examination using (EPIQ 7 Machine-Philips ultrasound \& Doppler). HCC appears as focal small or large mass, Multiple (multifocal) lesions of variable attenuation or Diffuse (infiltrative) lesion.

Typically, we found small lesion is relatively hypoechoic compared to normal hepatic parenchyma and large lesions appear heterogeneous due to variable contents, by contrast-enhanced ultrasound: (lesions showing arterial enhancement, decreased echogenicity or washout in Porto-venous phase also we exclude any portal venous thrombosis or absence intraluminal flow at the same setting).

CT scanner at our institute was (Aquilion PRIMCanon Medical) to detect hepatocellular carcinoma that is mainly showing vividly enhancement during late arterial phase after $30 \mathrm{~s}$ of IV contrast injection and washes out rapidly with hypo-attenuation in the portal venous and delayed phases compared to the rest of the liver, also detection of portal venous thrombus that is also confirmed by peripheral arterial enhancement of the lumen of the vein with the absent intraluminal flow at Portovenous phase [16].

MRI scanner was (Ingenia Philips Medical Systems), using different pulse sequences and imaging classification system (LI-RADS) to facilitate the diagnosis.

T1 weighted images: HCC appears iso- to hypo-intense lesion compared to the surrounding hepatic parenchyma; some hyperintensity is also seen if there is intratumoral fat content or hemorrhage.

Post-contrast T1 weighted images: the hypervascular lesions give rapid enhancement at the arterial phase and rapid washout with low signal lesion compared to the surrounding hepatic parenchyma at Porto-venous phase; sometimes we detect rim enhancement with a large central non-enhanced area of necrosis.
T2 weighted images: HCC appears of variable mainly hyper-intense lesions.

Diffusion-weighted images: HCC appears as an area of high signal (restricted diffusion) compared to the low signal at the ADC map $[17,18]$.

\section{Surgical procedures \\ Surgical procedures for open resection group}

Surgery was performed under general anesthesia; patients were supine in position. The incision sites depend on the tumor location. We started general abdominal exploration followed by liver inspection and palpation. Liver mobilization starts with the division of the falciform ligament and all adhesions to free the liver surfaces, get enough space to handle the IOUS probe [19]. IOUS is used to determine the accurate size, location, and relation to a large vessel or duct and detect the presence of any new lesion not discovered by preoperative imaging. IOUS was done for 32 patients (32/52 of surgical resection group). Intra-operative transducers used in the current study for IOUS of the liver are T-shaped transducer BK medical, type 8816, 4.3-10 MHz. We mark about one centimeter all around the lesion margin with diathermy as safety margin followed by liver resection with Habib needle, complete hemostasis confirmed and drain inserted (Fig. 2A, B).

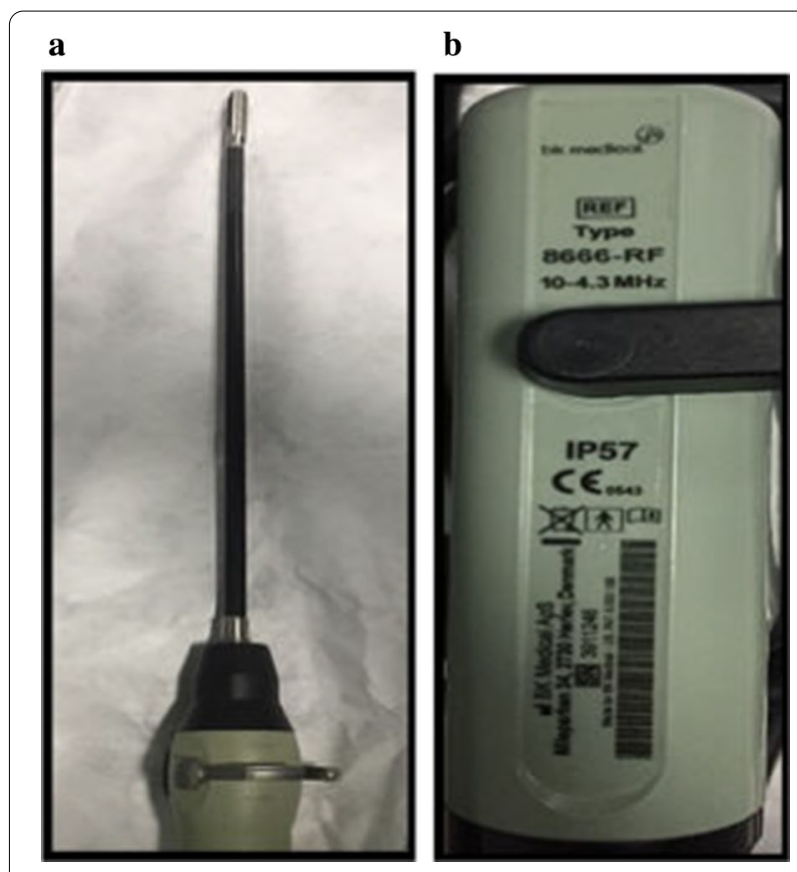

Fig. 2 A, B RFA technique used in the study was (USA). Equipment for RFA and ultrasonography (4-way laparoscopic transducer BK medical, type $8666-R F, 10-4.3 \mathrm{MHz}$, contact surface $30 \times 5 \mathrm{~cm}$ ) 


\section{Surgical procedures for LARFA group}

Pneumo-peritoneum and inflation pressure were maintained at $13 \mathrm{mmHg}$. The camera was introduced through the umbilical port. A second trocar was inserted in the left or right upper quadrant to allow the ultrasound probe. A third trocar was used for liver manipulation and insertion of towels to protect the viscera or diaphragm from the thermal effect of RFA. We started by peritoneal cavity exploration, liver mobilization with the division of the falciform ligament and all adhesions to free the liver surfaces, get enough space to handle the IOUS probes. Then performed laparoscopic IOUS (LIOUS) to confirm the accurate site, size, relation to large duct or vessel and detect the presence of any new lesion. The RF ablation needle was inserted percutaneously inside the center of the lesion with direct laparoscopic vision and confirmed by LIOUS (in the current study, we used 4-way laparoscopic transducer BK medical, type 8666-RF, 10-4.3 MHz, contact surface $30 \mathrm{X} 5 \mathrm{~cm}$ ). After complete ablation of the lesion, LIOUS is repeated to ensure complete tumor ablation; then, drain is inserted.

\section{Our technique and approach of IOUS (OPEN and Laparoscopic)}

We used the probe standoff technique (by using salinefilled abdominal cavity, saline filed glove, or saline-filled bag); this helps examination of superficial lesions, cirrhotic nodules, and blind areas of the liver, e.g., Segment VII. The movement plan's direction is the transverse, longitudinal, and oblique plans using probe rotation over a fixed point as well as the rocking or tilting methods to increase the field of views and assess the relationship between tumor and vascular structures. Our systematic approach for screening (right subcostal, subxiphoid, and umbilical scanning) is to start from the confluence of hepatic veins with IVC then trace all hepatic veins tell their origin, then go from the left portal vein next to the falciform ligament and follow its branches then reach the main portal vein, then from main portal vein to the right portal vein and its branches; finally, we confirm that all the anterior and posterior surface of the liver is included in the scan before the use of color Doppler examination.

\section{Statistical analysis}

Values for continuous variables are presented as medians and (ranges). Values for categorical-nominal variables are presented as frequencies (\%). For comparisons, quantitative variables were compared using Student's t test or the Wilcoxon rank-sum test, and categorical variables were compared using the Chi-squared or Fisher's exact test, as appropriate.

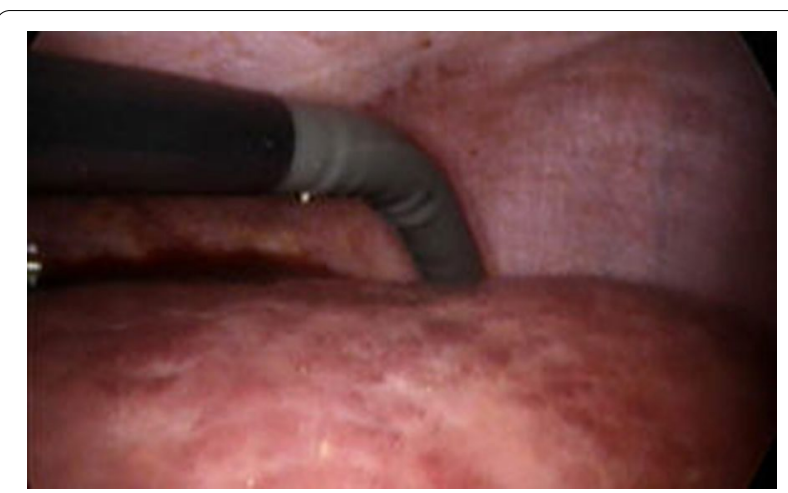

Fig. 3 IOUS for subdiaphragmatic HCC

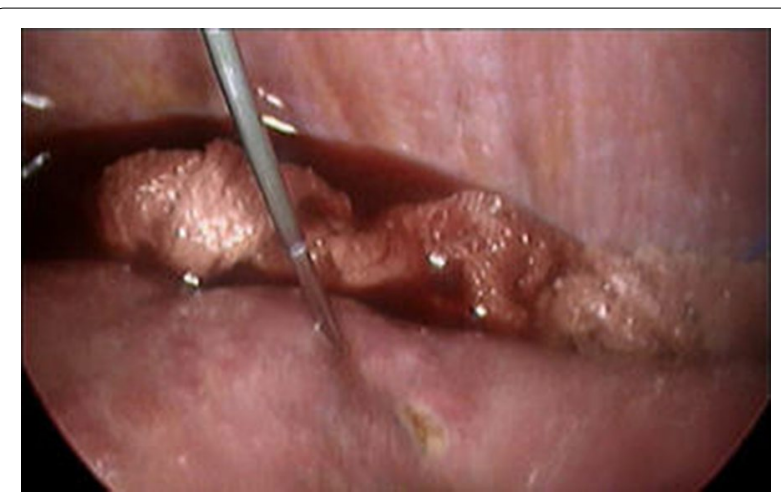

Fig. 4 LARFA of subdiaphragmatic HCC with towel

\section{Results}

In the current study, $76 \mathrm{HCC}$ patients were included. Open surgical liver resection was decided for 52 patients (open resection group) [32 patients with IOUS studied prospectively and 20 patients without IOUS as they were studied retrospectively] and laparoscopic-assisted RFA guided with IOUS was decided for 24 patients (LARFA group) (Figs. 3, 4).

\section{Results of open resection group}

Results are shown in Table 2 including mean operative time, free surgical margin, significant intraoperative bleeding, biliary leak, operative bed collection, and surgical wound infection, and mortality. The mean operative time was longer in the group done without IOUS, 100\% of patients performed with IOUS had free surgical margin by histopathology, while $90 \%$ of patient done without IOUS had free surgical margin and $10 \%$ had invaded surgical margin by histopathology. Significant intraoperative bleeding, biliary leak, operative bed collection, surgical wound infection were more in the group operated without IOUS. 
Table 2 Results of open resection group

\begin{tabular}{lll}
\hline & $\begin{array}{l}\text { Open resection } \\
\text { group with IOUS }\end{array}$ & $\begin{array}{l}\text { Open resection group } \\
\text { without IOUS }\end{array}$ \\
\hline $\begin{array}{l}\text { Mean operative time } \\
\text { (min) }\end{array}$ & $110 \pm 20$ & $125 \pm 20$ \\
$\begin{array}{c}\text { Free surgical margin } \\
n(\%)\end{array}$ & $32(100 \%)$ & $18(90 \%)$ \\
$\begin{array}{c}\text { Significant intra-opera- } \\
\text { tive bleeding } n \text { (\%) }\end{array}$ & $3(9.3 \%)$ & $4(20 \%)$ \\
$\begin{array}{c}\text { Biliary leak } n(\%) \\
\text { Operative bed collec- } \\
\text { tion } n \text { (\%) }\end{array}$ & $2(6.2 \%)$ & $3(15 \%)$ \\
$\begin{array}{c}\text { Surgical wound infec- } \\
\text { tion } n \text { (\%) }\end{array}$ & $3(9.3 \%)$ & $4(20 \%)$ \\
$\begin{array}{c}\text { Mean hospital stay } \\
\text { (day) }\end{array}$ & 7 & $2(10 \%)$ \\
\begin{tabular}{c} 
Mortality $n$ \\
\hline
\end{tabular} & Nil & 9
\end{tabular}

Table 3 Indications for ultrasound-guided LARFA

\begin{tabular}{ll}
\hline HCC location & $\mathbf{( n , \% )}$ \\
\hline Near bowel $(n, \%)$ & $15(62.5 \%)$ \\
Near large duct or vessel $(n, \%)$ & $6(25 \%)$ \\
Close to diaphragm $(n, \%)$ & $3(12.5 \%)$ \\
\hline
\end{tabular}

There was no perioperative mortality in the patients operated guided by IOUS while one case reported postoperative mortality in a patient operated without IOUS as that patient suffered from liver decompensation followed by hepatorenal failure.

\section{Results of LARFA group}

In the current study, 24 patients having 37 HCC lesions underwent LARFA. The indications for LARFA in those patients were having lesions in difficult locations as shown in Table 3. Twelve patients (50\%) had a single lesion, 11 (45\%) had two lesions, and 1 patient (5\%) had three lesions. The tumor diameter median was $2.6 \mathrm{~cm}$. Technical success was reported in $100 \%$, there was no conversion to open surgery, and all lesions were completely ablated as confirmed by LIOUS. The postoperative median hospital stay was 3 days with no perioperative mortality. The patients were followed up for at least one year. According to the SIR classification system [20], major complications were recorded in two patients (8.3\%) (one patient developed right portal vein thrombosis and another had subcapsular hematoma). Patients were treated conservatively with medical treatment. Minor complications like skin burn were recorded in 4 patients (16.6\%). Follow up with serum alpha-fetoprotein, tri-phasic CT, and/or MRI for all patients after the

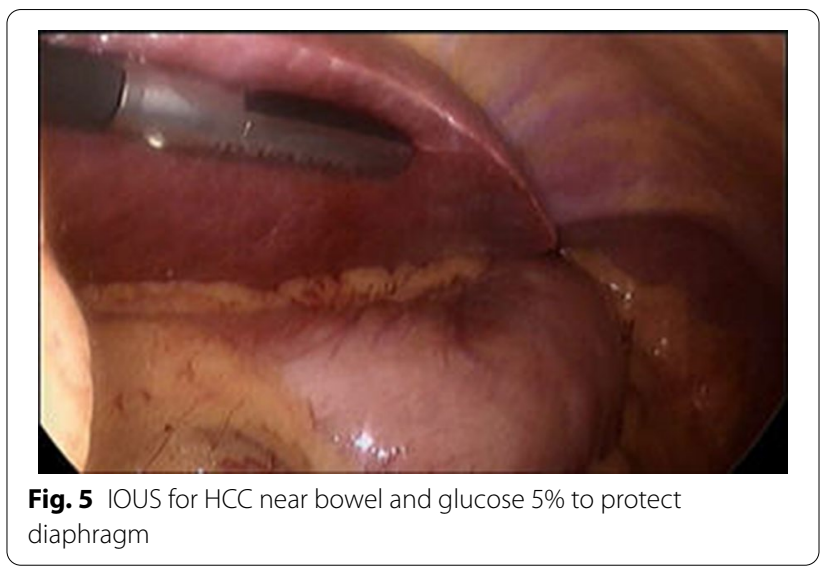

first month, every 3 months for the first year, and every 6 months later on. The first-month follow-up showed complete ablation for all patients (100\%), while the 12-month follow-up showed two cases $(8.32 \%)$ of recurrence, indicating that RFA assisted with LIOUS helped in achieving complete ablation (Figs. 5, 6A, B).

\section{Discussion}

Many previous studies discussed how IOUS can change the surgical strategy by the intraoperative diagnosis of new HCC lesions not diagnosed by preoperative imaging modalities like CT and MRI $[12,13]$.

This current study aims to detect the value of using IOUS on safety margin and outcome during liver resection and laparoscopic-assisted RFA in the management of HCC patients and our results proved that the use of IOUS is of great value either in the open resection or in LARFA of hepatic focal lesions.

With the use of IOUS in the open resection group, the mean operative time was less, there was no significant intra-operative bleeding, less biliary leak, less operative bed collection, less surgical wound infection, and all patients had free surgical margin. IOUS was a guide for better intraoperative assessment of the lesions and their nearby relation to large vessels or ducts and avoidance of injury to important structures so there was less postoperative morbidity. The other 20 cases studied retrospectively were done before the routine introduction of IOUS in hepatectomy operations in our institute, and their results showed longer operative time, longer hospital stay, bleeding, biliary leak and operative bed collection were more. These results are matching with Donadon $M$ and Torzilli G 2013 who concluded that IOUS minimizes postoperative complications and is mandatory for modern parenchyma-sparing hepatic surgery [19].

Guidance with IOUS has advantages over transabdominal imaging procedures regarding accessibility, 
$\mathbf{a}$

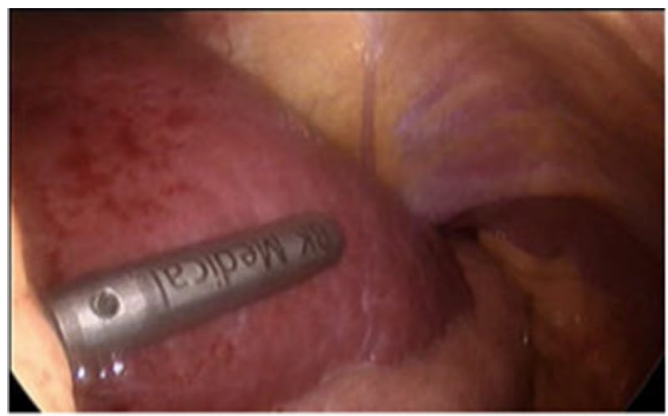

b

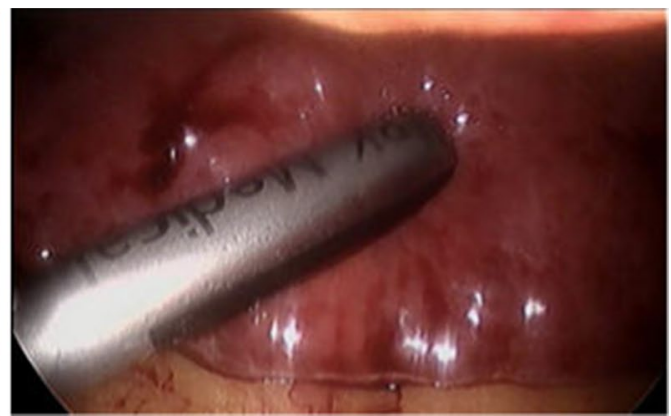

Fig. 6 A, B IOUS for HCC near bowel

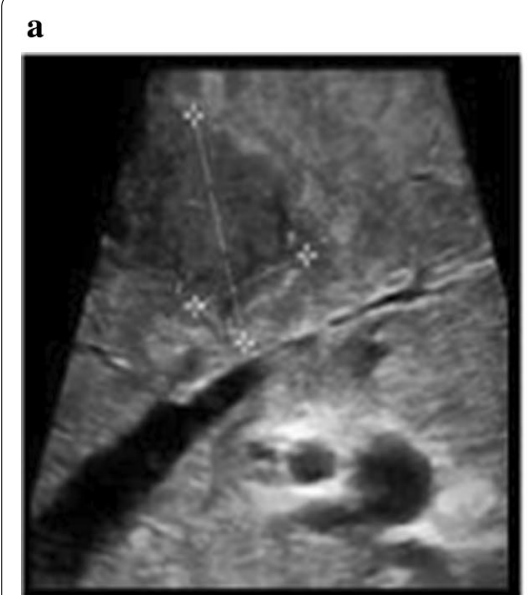

b

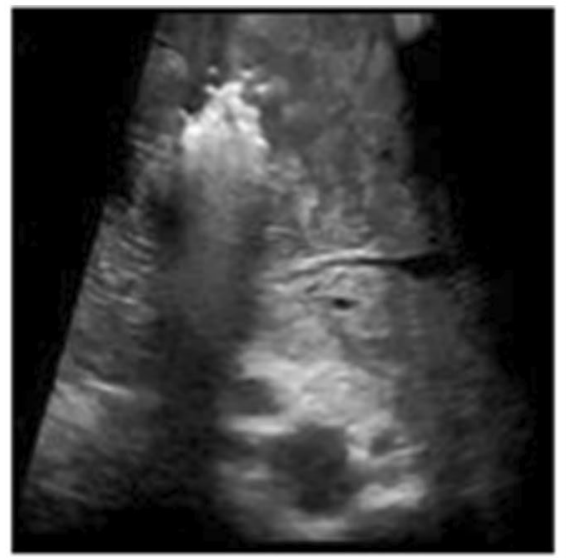

c

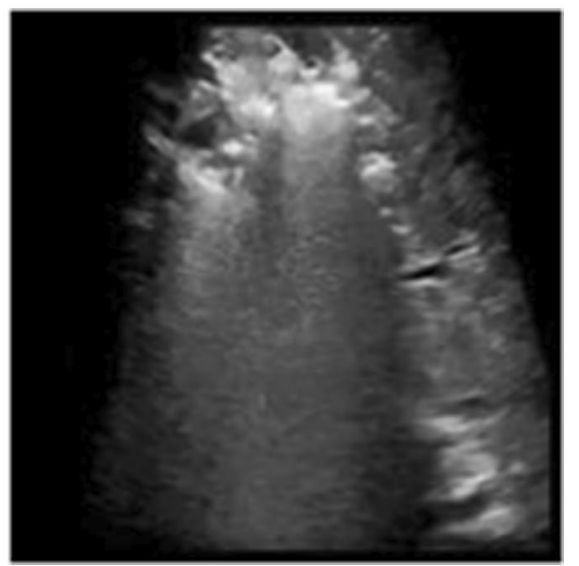

Fig. 7 A-C Laparoscopic ultrasound examination during LARFA laparoscopic radio-frequency ablation of right hepatic lobe segment VII HCC]. A Ultrasound image before starting of the ablation showing right lobe segment VII well defined hypo-echoic HCC away from the middle hepatic vein). B Ultrasound showing the lesion become echogenic due to gas bubbles during ablation. $\mathbf{C}$ Ultrasound showing successful complete ablation of the segment VII HCC

especially in procedures involving deep lesions or lesions hidden by overlying structures [21].

In the current study, 24 patients with 37 HCC lesions underwent LARFA. The indications for LARFA in those patients are being present in difficult locations. LARFA of HCC has a low rate of major complications, most of them related to bleeding from hepatic puncture sites or trocar accesses. We reported only one case of a hematoma, no local tumor spread observed, and no treatment-related mortality recorded. Our results are going with the results of Anna Sánchez-López et al. retrospective study done in Spain in 2015 on 32 patients with 37 tumors managed with LARFA and reported initial complete ablation in 94.6\% (35/37) lesions, while in the current study, it was $100 \%$ [22]. On contrary, the results of Yang W et al. 2015 were different as they had a high rate of major complications for the so-called difficult group was $4.9 \%$ [23]. This could be explained that they used percutaneous RFA and not laparoscopic-assisted RFA used in the current study, which helped in accurate needle insertion under direct vision and consequently decreased the rate of major complications. Using IOUS allows the performance of radical but conservative hepatic resection which means radical resection of the tumor with safety margin, but conservative to the liver with keeping as much as possible of liver tissue safely to avoid liver decompensation and improve patient survival (Fig. 7A-C).

\section{Conclusion}

IOUS is a cornerstone in liver surgery. It improves outcomes with less morbidity and mortality and helps to achieve free surgical margin. Using IOUS allows the performance of radical but conservative hepatic resection. 


\section{Abbreviations}

RFA: Radio-frequency ablation; HCC: Hepatocellular carcinoma; MWA: Microwave ablation; IOUS: Intra-operative ultrasound; LARFA: Laparoscopic-assisted radio-frequency ablation; BCLC: Barcelona-clinic liver cancer staging system for hepatocellular carcinoma.

\section{Acknowledgements}

Not applicable.

\section{Authors' contributions}

M.M. was involved in 1. substantial contribution to the conception of the study, 2. substantial contribution to the design of the study, 3. substantial contribution to the acquisition, analysis of the data, 4. substantial contribution to the interpretation of data, 5. substantial contribution to the creation of the final work, 6. substantial contribution to the study revision, and 7. substantial contribution to the accuracy or integrity of the submitted manuscript. A.A.Z. was involved in 1. substantial contribution to the conception of the study, 2. substantial contribution to the design of the study, 3. substantial contribution to the acquisition, analysis of the data, 4. substantial contribution to the interpretation of data, 5. substantial contribution to the creation of the final work, 6. substantial contribution to the study revision, and 7. substantial contribution to the accuracy or integrity of the submitted manuscript. A.A.E. was involved in 1. substantial contribution to the conception of the study 2. substantial contribution to the design of the study, 3. substantial contribution to the acquisition, analysis of the data, 4. substantial contribution to the interpretation of data, 5. substantial contribution to the creation of the final work, 6. substantial contribution to the study revision, and 7. substantial contribution to the accuracy or integrity of the submitted manuscript. E.I. was involved in 1. substantial contribution to the conception of the study, 2. substantial contribution to the design of the study, 3. substantial contribution to the acquisition, analysis of the data, 4. substantial contribution to the interpretation of data, 5. substantial contribution to the creation of the final work, 6 . substantial contribution to the study revision, and 7. substantial contribution to the accuracy or integrity of the submitted manuscript. N.G. was involved in 1. substantial contribution to the conception of the study, 2. substantial contribution to the design of the study, 3. substantial contribution to the acquisition, analysis of the data, 4. substantial contribution to the interpretation of data, 5. substantial contribution to the creation of the final work, 6. substantial contribution to the study revision, and 7. substantial contribution to the accuracy or integrity of the submitted manuscript. W.M.A. was involved in 1. substantial contribution to the conception of the study, 2. substantial contribution to the design of the study, 3. substantial contribution to the acquisition, analysis of the data, 4. substantial contribution to the interpretation of data, 5. substantial contribution to the creation of the final work, 6 . substantial contribution to the study revision, and 7. substantial contribution to the accuracy or integrity of the submitted manuscript. All authors read and approved the manuscript.

\section{Funding}

None.

\section{Availability of data and materials}

The datasets used and/or analyzed during the current study are available from the corresponding author on reasonable request.

\section{Declarations}

\section{Ethics approval and consent to participate}

Our study was approved by ethical and scientific committee-National Hepatology and Tropical Medicine Research Institute, Surgical Department, Cairo, Egypt, Ref. No. ITH 00105. Written informed consent form was obtained from every patient after detailed explanation of the study.

\section{Consent for publication}

A consent form is obtained from each patient, indicating that the procedures and data can be used in publications.

\section{Competing interests}

The authors declare that they have no competing interests.

\section{Author details}

${ }^{1}$ Surgical Department, National Hepatology and Tropical Medicine Research Institute, Cairo, Egypt. ${ }^{2}$ Department of Radiodiagnosis, Interventional Radiology and Medical Imaging, Faculty of Medicine, Menoufia University, Menoufia, Egypt. ${ }^{3}$ Tropical Medicine Department, National Hepatology and Tropical Medicine Research Institute, Cairo, Egypt. ${ }^{4}$ Internal Medicine Department, Faculty of Medicine, Cairo University, Cairo, Egypt. ${ }^{5}$ Radiology Department, National Hepatology and Tropical Medicine Research Institute, Cairo, Egypt.

Received: 19 March 2021 Accepted: 21 July 2021

Published online: 03 August 2021

\section{References}

1. Parkin DM, Bray F, Ferlay J, Pisani P (2005) Global cancer statistics, 2002. CA Cancer J Clin 55:74-108

2. Chenyang D, Mengying L, Zhuohang Z, Kuansheng M, Ping B (2013) Radiofrequency ablation versus hepatic resection for the treatment of early-stage hepatocellular carcinoma meeting Milan criteria: a systematic review and meta-analysis. World J Surg Oncol 11:190

3. Forner A, Llovet JM, Bruix J (2012) Hepatocellular carcinoma. Lancet 379:1245-1255

4. European Association For The Study Of The Liver European Organization For Research And Treatment Of Cancer (2012) EASL-EORTC clinical practice guidelines: management of hepatocellular carcinoma. J Hepatol 56:908-943

5. Lee JM, Park JW, Choi BI (2014) 2014 KLCSG-NCC Korea Practice Guidelines for the management of hepatocellular carcinoma: HCC diagnostic algorithm. Dig Dis 32:764-777

6. Topal B, Hompes D, Aerts R, Fieuws S, Thijs M, Pennickx F (2007) Morbidity and mortality of laparoscopic Vs. open radiofrequency ablation for hepatic malignancies. Eur J Surg Oncol 33:603-607

7. Siperstein A, Garland A, Engle K, Rogers S, Berber E, String A et al (2000) Laparoscopic radiofrequency ablation of primary and metastatic liver tumors. Tech. Consid Surg Endosc 14:400-405

8. Gravante G, Ong SL, Metcalfe MS, Bhardwaj N, Lloyd DM, Dennison AR (2011) The effects of radiofrequency ablation on the hepatic parenchyma: histological bases for tumor recurrences. Surg Oncol 20:237-245

9. Santambrogio R, Podda M, Zuin M, Bertolini E, Bruno S, Cornalba GP et al (2003) Safety and efficacy of laparoscopic radiofrequency ablation of hepatocellular carcinoma in patients with liver cirrhosis. Surg Endosc 17:1826-1832

10. Herbold T, Wahba R, Bangard C, Demir M, Drebber U, Stippel DL (2013) The laparoscopic approach for radiofrequency ablation of hepatocellular carcinoma-indication, technique and results. Langenbecks Arch Surg 398:47-53

11. Bartolotta TV, Taibbi A, Midiri M, De Maria M (2008) Hepatocellular cancer response to radiofrequency tumor ablation: contrast-enhanced ultrasound. Abdom Imaging 33:501-511

12. Lu Q, Luo Y, Yuan CX, Zeng Y, Wu H, Lei Z et al (2008) Value of contrastenhanced intraoperative ultrasound for cirrhotic patients with hepatocellular carcinoma: a report of 20 cases. World J Gastroenterol 14:4005-4010

13. Mogahed M, Abdelraouf A, Elkholy A, Abdellatif WM, Zytoon AA (2016) Effect of Intra Operative Ultrasonography on Change of Surgical Decision for Patients with Hepato cellular Carcinoma. Int J Radiol Radiat Ther https://doi.org/10.15406/ijrrt.2016.01.00006

14. Vauthey JN, Dixon E, Abdalla EK, Helton WS, PawlikTM, Taouli B et al (2010) American Hepato-Pancreato-Biliary Association; Society of Surgical Oncology; Society for Surgery of the Alimentary Tract: pretreatment assessment of hepatocellular carcinoma: expert consensus statement. HPB (Oxford) 12:289-299

15. Shukla JP, Pandey D, Rao PP, Shrikhande SV, Thakur MH, Arya S et al (2005) Impact of intra-operative ultrasonography in liver surgery. Indian J Gastroenterol 24:62-65

16. Reynolds AR, Furlan A, Fetzer DT et al (2015) Infiltrative hepatocellular carcinoma: what radiologists need to know. Radiographics 35(2):371-386

17. Illatt JM, Hussain HK, Adusumilli S et al (2008) MR Imaging of hepatocellular carcinoma in the cirrhotic liver: challenges and controversies. Radiology 247(2):311-330 
18. Parente DB, Perez RM, Eiras-Araujo A et al (2012) MR imaging of hypervascular lesions in the cirrhotic liver: a diagnostic dilemma. Radiographics 32(3):767-787

19. Donadon M, Torzilli G (2013) Intraoperative ultrasound in patients with hepatocellular carcinoma: from daily practice to future trends. Liver Cancer 2(1):16-24

20. Ahmed M, Solbiati L, Brace CL, Breen DJ, Callstrom MR, Charboneau JW et al (2014) Image guided tumor ablation: standardization of terminology and reporting criteria-a 10-year update. Radiology 273:241-260

21. Joo J (2015) The role of intraoperative ultrasonography in the diagnosis and management of focal hepatic lesions. Ultrasonography 34(4):246-257

22. Sánchez-López A, Pallisera-Lloveras A, Saiz-Mendiguren R, Ferrer-Marsal M, Vicens Arbona JC, Cifuentes-Ródenas JA et al (2015) Laparoscopic radiofrequency ablation for hepatocellular carcinoma. Hepatoma Res 1:86-91

23. Yang W, Yan K, Wu GX, Wu W, Fu Y, Lee JC et al (2015) Radiofrequency ablation of hepatocellular carcinoma in difficult locations: strategies and long-term outcomes. World J Gastroenterol 21(5):1554-1566

\section{Publisher's Note}

Springer Nature remains neutral with regard to jurisdictional claims in published maps and institutional affiliations.

\section{Submit your manuscript to a SpringerOpen ${ }^{\circ}$ journal and benefit from:}

- Convenient online submission

- Rigorous peer review

- Open access: articles freely available online

- High visibility within the field

- Retaining the copyright to your article

Submit your next manuscript at $\boldsymbol{\nabla}$ springeropen.com 